\title{
Response of acute cerebral lupus in childhood to pulse methylprednisolone in reduced dosage
}

\author{
OWEN HANMER AND DAVID SALTISSI \\ From the Armed Forces Hospital, Riyadh, Saudi Abrabia
}

SUMMARY Intravenous methylprednisolone pulse therapy in a reduced dose of $10 \mathrm{mg} / \mathrm{kg}$ on three consecutive days was successfully used in the treatment of a 9 year old girl with acute cerebral lupus in coma. It is recommended for further evaluation in children with severe primary $\frac{\mathrm{O}}{2}$ central nervous system (CNS) disease.

Key words: lupus erythematosus-systemic, coma, collagen diseases.

Neurological involvement affects almost half of children with systemic lupus erythematosus (SLE) and remains a potential cause of death. ${ }^{1}$ The essential role of steroids in severe SLE is undoubted, but when used alone in children oral prednisolone in high dosage is effective in only half of those with severe CNS disease. The combination of steroid and cytotoxic therapy has appeared to be more effective, and intravenous steroid pulse therapy has also been employed. ${ }^{2}$ Intravenous methylprednisolone (IV MP) in five daily pulses of $30 \mathrm{mg} / \mathrm{kg}$ is well established in the management of renal $\mathrm{SLE}^{3}$ and has been recommended for use in non-renal SLE uncontrolled by other means, ${ }^{45}$ but as yet there are few reports of its use in children with CNS disease.

We describe the successful response of a child with severe primary CNS disease to IV MP in much lower dosage.

\section{Case report}

A 9 year old Saudi girl presented with a short history of anorexia, weight loss, and fever and a two year history of intermittent polyarthralgia. She was thin and unwell, with a small subcutaneous nodule on the dorsum of her hand, a generalised discreet lymphadenopathy, limited movement of wrists, knees,

Accepted for publication 10 December 1985

Correspondence to Dr Owen Hanmer, Royal Hospital for Sick Children, Sciennes Road, Edinburgh. and cervical spine, mild swelling of her wrists, but no acute arthritis or other abnormality.

There was no history of neurological disorder, drug therapy, or previous illness. Her parents were unrelated. She has an indentical twin, but there was no significant history of disease.

Investigation showed an $\mathrm{Hb}$ of $10.4 \mathrm{~g} / \mathrm{dl}(104 \mathrm{~g} / \mathrm{l})$, erythrocyte sedimentation rate (ESR) $55 \mathrm{~mm} / 1 \mathrm{st} \mathrm{h}$, $\mathrm{C}$ reactive protein (CRP) $24 \mu \mathrm{g} / \mathrm{l}$, positive LE cell test, raised antinuclear antibody titre $1 / 5120$ and anti-dsDNA titre $1 / 640$, and a positive lupus band test. There were normal values for $\mathrm{C} 3$ complement $(142 \mathrm{mg} / \mathrm{dl}(1.42 \mathrm{~g} / \mathrm{l}))$, white blood cells, platelets, urea, creatinine, electrolytes, liver function tests, prothrombin time (PT), partial thromboplastin time (PTT), creatinine clearance, urinary protein excretion, antistreptolysin $\mathrm{O}$ titre, Coombs' test, and rheumatoid arthritis latex test (negative).

She was given aspirin $100 \mathrm{mg} / \mathrm{kg} /$ day (serum level $25 \mathrm{mg} / \mathrm{dl}$ ) without improvement, and 14 days later $\mathcal{N}$ developed a characteristic facial eruption. She was $N$ treated with chloroquine $3 \mathrm{mg} / \mathrm{kg} /$ day and topical $\mathrm{N}$ steroids and became apyrexial but increasingly withdrawn.

After two days she rapidly deteriorated and developed choreoathetosis, extensor plantar re- $\stackrel{\mathbb{Q}}{\mathscr{Q}}$ sponses, coma, and gingival haemorrhage. She was normotensive with normal full blood count, fibrin degradation products, blood glucose, urea, creati- $\frac{\mathbb{D}}{\mathbb{D}}$ nine, electrolytes, cerebrospinal fluid and computed $\stackrel{\odot}{\vec{D}}$ tomographic brain scan, but her ESR was $69 \mathrm{~mm} / \varrho$ 1st h, CRP $60 \mu \mathrm{g} / \mathrm{l}$, serum complement $36 \mu \mathrm{g} / \mathrm{l}$, anti- 
dsDNA titre 1/10 240, PT 42/13, PTT 55/37, and serum aspartate transaminase (AST) $180 \mathrm{IU} / \mathrm{l}$.

A diagnosis of primary cerebral lupus was made, and she was treated with IV MP in three pulses of $10 \mathrm{mg} / \mathrm{kg}$ given by slow infusion over 30 minutes on consecutive days and with azathioprine $2 \mathrm{mg} / \mathrm{kg} / \mathrm{day}$. She remained in a coma for 60 hours but by 72 hours had regained consciousness and by one week appeared neurologically normal. Her AST, PT, and PTT values rapidly returned to normal.

After 14 days she was asymptomatic, happy and sociable, and her ESR was $40 \mathrm{~mm} / 1 \mathrm{st} \mathrm{h}$, CRP 12 $\mu \mathrm{g} / \mathrm{l}, \mathrm{C} 3$ complement $77 \mu \mathrm{g} / \mathrm{l}$, and anti-dsDNA titre $1 / 320$. Azathioprine was discontinued after an eight week course and oral methylprednisolone continued in reducing dosage without complication.

\section{Discussion}

In CNS lupus, convulsions, cerebral dysfunction, neuropathy, strokes, and chorea may occur together or in isolation and are often heralded by psychiatric disturbance.

We have no evidence that this patient's coma was not primarily due to cerebral lupus. There is no entirely satisfactory laboratory test of CNS involvement so diagnosis is essentially clinical and relies on the exclusion of cerebral dysfunction secondary to other disorders, lupus nephritis, and drug therapy. Liver dysfunction and prolonged PT and PTT can arise as an early complication of aspirin therapy, ${ }^{6}$ and when this is stopped there is a characteristically rapid return to normal values as seen in this patient. It is improbable that her clotting defect was primarily due to SLE or her coma the result of hepatotoxicity.

In this patient IV MP in a bolus of $10 \mathrm{mg} / \mathrm{kg}$ on three consecutive davs was clinically effective and improved levels of ds-DNA antibody and C3 complement. It is unlikely that azathioprine could have contributed to such a rapid response. Large intravenous doses of corticosteroid have been used in a wide variety of disorders and appear to have effects on inflammation and immunoregulation not seen at lower doses. ${ }^{5}$ Yancey et al reported the use of high dose IV MP in three children and combined oral steroid and cytotoxic therapy in five children after oral prednisolone alone was ineffective in 10 of 16 children with CNS lupus and recommended combined oral therapy, with IV MP for use when this was ineffective. ${ }^{2}$ This use of IV MP may have influenced others but there are few other reports of its use. ${ }^{7} 8$

When IV MP is administered as a short intensive course many of the usual side effects of conventional high dose oral therapy may be avoided, but rapid infusion has occasionally been associated with sudden death, possibly related to acute shifts in potassium. Single doses of IV MP do not appear to have a significant effect on the risk of infection, but the effect of multiple dosage is unclear and may not be without risk. ${ }^{5}$

Administration of IV MP in this lower dosage may minimise toxicity without compromising its apparent value as a first line treatment for severe CNS lupus.

\section{References}

1 Wallace C, Schaller J G, Emery H, Wedgewood R. Prospective study of childhood systemic lupus erythematosus (SLE). Arthritis Rheum 1978; 21: 599-600.

2 Yancey C L, Doughty R A, Athreya B H. CNS involvement in childhood systemic lupus erythematosus. Arthritis Rheum 1981; 24: 1389-95.

3 Levinsky R J, Cameron J S, Soothill J F. Serum immune complexes and disease activity in lupus nephritis. Lancet 1977; i: 564-7.

4 Isenberg D A, Morrow W J W, Snaith M L. Methylprednisolone pulse therapy in the treatment of systemic lupus erythematosus. Ann Rheum Dis 1982; 41: 347-51.

5 Kimberly R P. Pulse methylprednisolone in SLE. Clin Rheum Dis 1983; 9: 261-78.

6 Hughes G R V. The treatment of SLE: the case for conservative management. Clin Rheum Dis 1983: 9: 299-313.

7 Fessel W J. Megadose corticosteroid therapy in systemic lupus erythematosus. J Rheumatol 1980; 7: 486-500

8 Eyanson S, Passo M H, Aldo-Benson M A, Benson M D. Methylprednisolone pulse therapy for non-renal lupus erythematosus. Ann Rheum Dis 1980; 39: 377-80. 